\title{
Special Issue: New Directions in Research Examining Crime Over the Life-Course
}

\author{
Wesley G. Jennings
}

Published online: 20 April 2010

(C) Southern Criminal Justice Association 2010

\section{Editorial Introduction}

It is my pleasure to introduce you to my special issue on "New Directions in Research Examining Crime over the Life-Course." The overall goal and purpose of this special issue is to disseminate theoretically grounded and empirically sound research that investigates the complex nature of studying crime over the life-course going beyond merely stating that prior offending is related to future offending. The series of high-quality articles included in this special issue are from diverse methodological approaches and utilize advanced statistical techniques and longitudinal data to explore offending over various developmental periods of the life-course.

Before discussing the contribution of each article, it is necessary for me to emphasize why longitudinal research is particularly important for our discipline. Longitudinal research in its most basic form (as applied to the study of crime), involves the identification of a cohort at birth and following that group of individuals throughout their life, or at least long enough to capture the termination of the majority of criminal careers (Blumstein et al. 1986, p. 104). The longitudinal method allows for a specified cohort's level of involvement in crime to be traced as the cohort, itself, matures (Greenberg 1985). This knowledge is crucial for detecting causal factors or sequences that associate individual characteristics or certain events to consequential offending (Blumstein et al. 1988). Longitudinal data also permits the use of complex behavioral models because they allow one to examine the effects of missing or unobserved variables that may be correlated with crime (i.e., also known as the unobserved heterogeneity problem). It is often the case that even among people who have similar characteristics (race, age, sex) there is a substantial amount of heterogeneity. Thus, it is important to

\footnotetext{
W. G. Jennings $(\bowtie)$

Department of Justice Administration, University of Louisville,

Brigman Hall, Room 215, Louisville, KY 40291, USA

e-mail: wgjenn01@gwise.louisville.edu
} 
utilize longitudinal models or run the risk of using mis-specified models and producing inconsistent parameter estimates (see Nagin 2005).

These issues combined with the recent emergence and maturation of developmental and life-course criminology (Moffitt 1993; Farrington 2003; Jennings and Piquero 2009; Laub and Sampson 2003; Sampson and Laub 1993) and criminal careers research (Piquero et al. 2003, 2007; Piquero et al. 2010) have led to a surge in the number of publications that focus on the stability and change in offending over time. Furthermore, this research has been influential in identifying salient risk and protective factors as well as life transitions (or turning points) that serve to increase an individual's likelihood for following an adolescent-limited or a chronic pathway of offending or may, in fact, function as buffers that promote desistance from delinquency and crime.

Provided with this background, I now turn toward discussing each of the articles included in this special issue with a particular focus on their unique and substantively important contributions to the developmental/life-course literature and criminal careers research. In the first article, "Incarceration during the Transition to Adulthood: A Snapshot of At-Risk Males at 25," Stacey Bosick and Angela Gover draw on longitudinal data from the Pittsburgh Youth Study and offer an exploratory analysis of life events experienced by at-risk males by age 25 . Using latent class cluster analysis, they find evidence suggesting that incarceration can and should be considered a significant life event (e.g., transition, turning point) that can have a long term effect on an at-risk male's life-course offending pathway. These results provide a unique contribution to the literature in that they demonstrate that incarceration is a key turning point in an individual's life that alters their behavioral trajectory much like Sampson and Laub argue that transitions such as marriage, employment, and military service can influence offending.

In the second article, "A Life-Course Perspective on Stress, Delinquency and Young Adult Crime," John Hoffmann investigates the relationship between Agnew's General Strain Theory (GST) and delinquent behavior and young adult crime. Relying on longitudinal data from the Family Health Study and utilizing negative binomial variations of general estimating equations (GEEs), his results indicated that there is a positive association between experiencing strainful life events and delinquent behavior and young adult crime. Additional analysis also revealed significant interactive effects between delinquent peer associations and strain. These results provide a welcomed contribution to the GST literature as there is very little longitudinal research in this area. Furthermore, considering the strong role that delinquent peer associations seemed to play in the strain-crime relationship, future GST studies that do not account for its influence may be running the risk of being mis-specified.

The third article, "Trajectories of Physical Aggression among Hispanic Urban Adolescents and Young Adults: An Application of Latent Trajectory Modeling from Ages 12 to 18," Mildred Maldonado-Molina et al. offer a longitudinal assessment of the effect of a number of key risk and protective factors on the trajectories of physical aggression among a sample of urban at-risk Hispanic youth residing in Chicago. Relying on Nagin and Land's (1993) group-based trajectory modeling technique, their results revealed five distinct trajectories of physical aggression: non-aggressive, low stable, escalators, early-rapid desistors, 
and high aggression/moderate desistors. Furthermore, several traditional risk factors (indirect exposure to alcohol, mental health issues, negative alcoholrelated attitudes, and threatening to fight) as well as ethnic-specific protective factors (e.g., language preference/speaking Spanish in the home) significantly distinguished the group-based trajectories. Maldonado-Molina et al.'s results provide a much needed contribution to the developmental/life-course literature and criminal careers research specifically, considering that Hispanics are grossly underrepresented in studies on delinquency and crime. In addition, their identification of traditional and ethnic-specific risk and protective factors is of great importance for policy-making and programming.

In the fourth article, "Criminal Offender Trajectories and (White-Collar) Occupational Prestige," Nicole Piquero et al. provide a unique application of the trajectory method to examine whether certain offending trajectories "knife-off" individuals' employment opportunities at age 48. Applying Nagin and Land's (1993) group-based trajectory modeling technique to the criminal careers of several hundred South London males who were part of the Cambridge Study in Delinquent Development, their results suggested that high-rate chronic offenders are the least likely trajectory group to hold prestigious white-collar jobs at age 48. In contrast, individuals who were classified as non-offenders were the most likely to be in highstatus occupational positions. N. Piquero et al.'s results offer a substantial contribution to both the developmental/life-course literature and criminal careers research and the white-collar crime literature considering that no study to date has linked white-collar occupational status to trajectories of offending. Furthermore, this article also provides another much needed contribution to the literature by identifying a neglected outcome (e.g., employment in white-collar occupations) associated with offending trajectories.

In the fifth article, "A Longitudinal Exploration of the Effect of Official Processing and Sanctioning on the Academic and Criminal Careers of College Students," Dave Khey et al. provides one of the most unique contributions to the long line of research investigating offending among college students. Using an impressive compilation of official data from a number of law enforcement agencies, Khey et al. examined the effect of official processing and sanctioning of college student offending on the academic careers and criminal careers of a sample of college students from a large university in a southeastern college town. The multivariate results suggested that the frequency of offending and the severity of offending were risk factors for dropping out of college/or being dismissed from college for academic reasons, whereas membership in a greek organization (e.g., fraternity or sorority) appeared to have a negative effect on dropping out/being dismissed. Or in other words, college students who were members of a greek organization were less likely to drop out or be dismissed from college for academic reasons. Furthermore, Khey et al.'s additional analysis indicated that the type and severity of punishment had a significant effect on the likelihood that a college student would recidivate. These results provide a substantial contribution to literature because college student offending has been virtually absent from the developmental/life-course literature and criminal careers research (for an exception, see Khey et al. 2009). In addition, the overwhelming majority of previous research examining offending among college students is 
based on cross-sectional and self-report data. Thus, Khey et al.'s longitudinal focus and use of official data on college student offending makes this study particularly unique and a welcomed addition to the college student offending literature.

In the sixth and final article in this special issue, "Monetary Costs of Gender and Ethnicity Disaggregated Group-Based Offending" Mark Cohen et al. present a rather unique intersection of the developmental/life-course literature and criminal careers research with economics. Specifically, relying on data from Tracy et al.'s (1990; Tracy and Kempf-Leonard 1996) Second Philadelphia Birth Cohort and using Nagin and Land's (1993) group-based trajectory modeling technique, Cohen et al. estimated gender and ethnicity-disaggregated trajectories which revealed interesting similarities and differences when comparing male and female offending trajectories as well as displaying noticeable similarities and differences when comparing White, African American, and Hispanic offending trajectories. While these results are unique in their own right to the developmental/life-course literature and criminal careers research, Cohen et al. take their analysis one step further by estimating and attaching willingness-to-pay (WTP) costs to each individual's offending. Their results indicated that male offending trajectories cost substantially more than female offending trajectories and that African American offending trajectories cost the most of any ethnic group followed by Hispanics and Whites. Furthermore, the least prevalent offending trajectory group (e.g., the chronic offenders) accounted for nearly half of the total costs of each of the sub-group's (e.g., male or female, White, African American, or Hispanic) total offending costs. The results from this study provide a unique contribution to the literature in that Cohen et al. demonstrate the similarities and differences in gender and ethnicity-disaggregated offending trajectories (which are noticeably scant in the developmental/life-course literature and criminal careers research). Furthermore, their attachment of monetary costs to the crimes committed by this cohort reveals a very intriguing picture for academics and policymakers. Specifically, the costs of crime are differentially distributed across offender trajectories, with chronic offending trajectories being responsible for the most substantial costs (and often the majority of the total costs).

Taken together, each of the six articles included in this special issue on "New Directions in Research Examining Crime over the Life-Course" offer two substantial contributions to the developmental/life-course literature and criminal careers research. First, all six of the articles utilize longitudinal data from large samples. Second, all six of the articles use advanced multivariate analytical techniques that may serve as examples for how future studies in this area should proceed with regard to research design and statistical modeling. Notwithstanding these two more general albeit important contributions, each of the articles in this special issue also provides a unique contribution to neglected areas of the developmental/life-course literature and criminal careers research. For instance, Stacey Bosick and Angela Gover argue for considering incarceration as a life transition/turning point that has an adverse effect on an individual's pathway of offending. John Hoffman's article focuses on applying Agnew's General Strain Theory (GST) to life-course criminology. Maldonado-Molina et al.'s article investigates trajectories of physical aggression among Hispanics, which have been virtually absent from discussions of life-course criminology (for an exception, see Maldonado-Molina et al. 2009). N. Piquero et al.'s article is the first of its kind to demonstrate the effect of offending trajectories 
on occupational outcomes in middle adulthood. In contrast, Khey et al.'s article not only shows the effect that offending can have on college students' academic careers, their results also emphasize the effect that sanctions can exert on college students' academic and criminal careers. Finally, Cohen et al.'s article displays the variability in offending trajectories once they are disaggregated by gender and ethnicity. More importantly, Cohen et al.'s results reveal the disproportionate costs that chronic offending trajectories account for and that this finding is consistent across gender and ethnicity-disaggregated offending trajectories.

In the end, I would like to offer a sincere thank you to the members of the Executive Board of the Southern Criminal Justice Association and to the current editor, Dr. George E. Higgins, and managing editor, Emmaleigh Kirchner, of the American Journal of Criminal Justice for allowing me the opportunity to be a Guest Editor for this special issue and providing me with assistance for taking this special issue to production. Finally, I also would like to extend my gratitude to all of the reviewers who played vital roles in the review process that ultimately improved the quality of each of the articles that are included in this special issue. I hope that you enjoy reading this special issue and that its contents not only provide a pleasurable read, but that all of the articles have more importantly taken the first step in advancing the current methodological and empirical state of developmental/life-course criminology and criminal careers research.

Sincerely,

Wesley G. Jennings, Ph.D.

Guest Editor

\section{References}

Blumstein, A., Cohen, J., Roth, J.A., \& Visher, C.A (eds.). (1986). Criminal careers and "career criminals," vol 1. Report of the Panel on Criminal Careers, National Research Council. Washington, D.C.: National Academy of Sciences.

Blumstein, A., Cohen, J., \& Farrington, D. P. (1988). Criminal career research: its value for criminology. Criminology, 26, 1-35.

Farrington, D. P. (2003). Developmental and life-course criminology: key theoretical and empirical issuesThe 2002 Sutherland Address Award. Criminology, 41, 221-255.

Greenberg, D. F. (1985). Age, crime, and social explanation. American Journal of Sociology, 91, 121.

Jennings, W. G., \& Piquero, A. R. (2009). Life-course criminology. In J. M. Miller (Ed.), 21st century criminology: A reference handbook (pp. 262-270). Thousand Oaks: Sage.

Khey, D. N., Jennings, W. G., Lanza-Kaduce, L., \& Frazier, C. (2009). An exploration into the factors associated with specialization among college student computer criminals. Criminal Justice Studies, 22, 421-434.

Laub, J. H., \& Sampson, R. J. (2003). Shared beginnings, divergent lives: Delinquent boys to age 70. Cambridge: Harvard University Press.

Maldonado-Molina, M. M., Piquero, A. R., Jennings, W. G., Bird, H., \& Canino, G. (2009). Trajectories of delinquent behaviors among Puerto Rican children and adolescents at two sites. Journal of Research in Crime and Delinquency, 46, 144-181.

Moffitt, T. E. (1993). Adolescent-limited and life-course-persistent antisocial behavior: a developmental taxonomy. Psychological Review, 100, 674-701.

Nagin, D. S. (2005). Group-based modeling of development. Cambridge: University of Harvard Press. 
Nagin, D. S., \& Land, K. C. (1993). Age, criminal careers, and population heterogeneity: specification and estimation of a nonparametric, mixed poisson model. Criminology, 31, 327-362.

Piquero, A. R., Farrington, D. P., \& Blumstein, A. (2003). The criminal career paradigm. Crime and justice: An annual review of research, Vol. 30 (pp. 359-506). Chicago: University of Chicago Press.

Piquero, A. R., Farrington, D. P., \& Blumstein, A. (2007). Key issues in criminal career research. Cambridge: Cambridge University Press.

Piquero, A. R., Jennings, W. G., \& Reingle, J. (2010). Criminal careers. In F. Cullen \& P. Wilcox (Eds.), Encyclopedia of criminological theory. Thousand Oaks: Sage.

Sampson, R. J., \& Laub, J. H. (1993). Crime in the making: Pathways and turning points through life. Cambridge: Harvard University Press.

Tracy, P. E., \& Kempf-Leonard, K. (1996). Continuity and discontinuity in criminal careers. New York: Plenum.

Tracy, P. E., Wolfgang, M. E., \& Figlio, R. M. (1990). Delinquency careers in two birth cohorts. Chicago: University of Chicago Press. 